\title{
ERRATUM
}

\section{Multi-analytical characterization of paper samples exhibiting foxing stains}

Relvas, C, Nunes, M, Figueira, F, Campelo, J, Candeias, A, Caldeira, AT, Ferreira T

doi:http://dx.doi.org/10.1017/S1431927614014093. Published by Cambridge University Press, 10 September 2015.

It is regretted that the originally published version of "Multi-analytical characterization of paper samples exhibiting foxing stains" by Relvas et al. was not the authors' final amended version. The editors apologize for this oversight and reproduce the correct version of this paper in its entirety below.

\section{References:}

[1] Relvas, C, Nunes, M, Figueira, F, Campelo, J, Candeias, A, Caldeira, AT, Ferreira T. Multi-analytical characterization of paper samples exhibiting foxing stains. Microsc. \& Microanal., 21:S6 (2015), pp. 78-79 (doi:10.1017/S1431927614014093) 


\title{
Multi-analytical characterization of paper samples exhibiting foxing stains
}

\author{
Relvas, $\mathrm{C}^{*}$, Nunes, $\mathrm{M}^{*}$, Figueira, $\mathrm{F}^{* *}$, Campelo, $\mathrm{J}^{* *}$, Candeias, $\mathrm{A}^{*}$, Caldeira, $\mathrm{AT}^{*}$, Ferreira $\mathrm{T}^{*}{ }^{\sharp}$ \\ *HERCULES Laboratory and Évora Chemistry Centre, Évora University, Évora, Portugal \\ *** José Figueiredo Laboratory, General Directorate for Cultural Heritage, Lisbon, Portugal \\ ${ }^{\Phi}$ Email: tasf@uevora.pt
}

Deterioration of graphical documents can occur naturally as a result of aging, but it can be accelerated by poor manufacturing constituents or conditions. One indicator of deterioration can be discoloration or staining of the surface [1-3]. Among these paper discoloration processes is foxing, which has been actively researched since the 1930s. Our attention herein is focused on trying to elucidate its causes and to establish protocols for detection, prevention and treatment. This foxing phenomenon occurs in the form of small isolated patches of discoloration that are typically rust, brown or yellowish toned and limited in size, with sharp or jagged edges; it is often punctiform and sometimes circular [4]. A long discussion about the origin of foxing has been undertaken, being the major causes attributed to fungal activity or to chemical origin. In fact, sometimes biological attack is the only factor observed, while in others metal-induced degradation is present and interaction between both factors can also be found [5]. During the last few decades, different analytical techniques have been used for the study of the foxing processes; nevertheless there is still much to be done $[4,5]$.

Four different foxed papers from the XX century, labelled P1, P2, P3 and P7, were studied. Characterization of paper samples and morphological aspects of foxing was undertaken by analytical techniques and imaging: photography and macro-photography under standard light, UV/Vis fluorescence light and raking light; light microscopy; variable pressure scanning electron microscopy with energy dispersive X-ray spectrometry (VPSEM/EDS) and attenuated total reflection Fourier transform infrared spectroscopy (ATR-FT-IR). Biological colonization was also studied in order to evaluate the influence of microorganisms in foxing.

Photographic imaging allowed to evaluate the natural colours of paper samples and their state of degradation, namely, the presence of dirt, foxing stains, wear, and others (Table 1). The foxing stains of P3 sample were the only ones to exhibit fluorescence under UV light. Morphological aspects of the foxing stains were observed by SEM/EDS operating in variable pressure conditions (pressure of $20 \mathrm{~Pa}$ in the chamber). Two different typologies were devised. In samples P1, P2 and P3, fibre disruption was observed in the foxed areas (Figure 1), when compared with the non-affected areas of those samples. As to sample P7, a localized accumulation of particles was observed in the foxed areas, which were confirmed to be a calcium salt due to Ca detection by EDS analysis. Different fillers used in paper production were also estimated through EDS. ATR-FT-IR complemented the study and was particularly adequate to evaluate the existence of biotic attack in the foxed areas of all the papers. ATRFT-IR was also able to supply information about the fillers and the FT-IR bands related to cellulose suggesting alterations of the cellulose structure in the foxed areas (Figure 2). Fungi belonging to the main genera Penicillium spp. were isolated from all the paper samples.

[1] Abdel-Maksoud, G., Measurement, 44, 1606-1617, 2011

[2] Castro, K., et al., Analytica Chimica Acta, 623, 187-194, 2003

[3] Goltz, D., et al., Journal of cultural heritage, 11, 19-26, 2010

[4] Manente, S., et al., International Biodeterioration \& Biodegradation, 74, 99-108, 2012

[5] Buzio, R., et al., Applied Physics A, 79, 383-387, 2004 
Table 1. Photographic and optical microscopy study

\begin{tabular}{|c|c|c|c|c|}
\hline Sample & $\begin{array}{c}\text { Standard } \\
\text { Light }\end{array}$ & $\begin{array}{l}\text { UV/Vis } \\
\text { fluorescence }\end{array}$ & Raking light & $\begin{array}{c}\text { Optical } \\
\text { microscopy } \\
(\mathbf{6 . 3 x})\end{array}$ \\
\hline P1 & & & & \\
\hline $\mathbf{P 2}$ & & & & \\
\hline P3 & & & & \\
\hline P7 & & & & \\
\hline
\end{tabular}

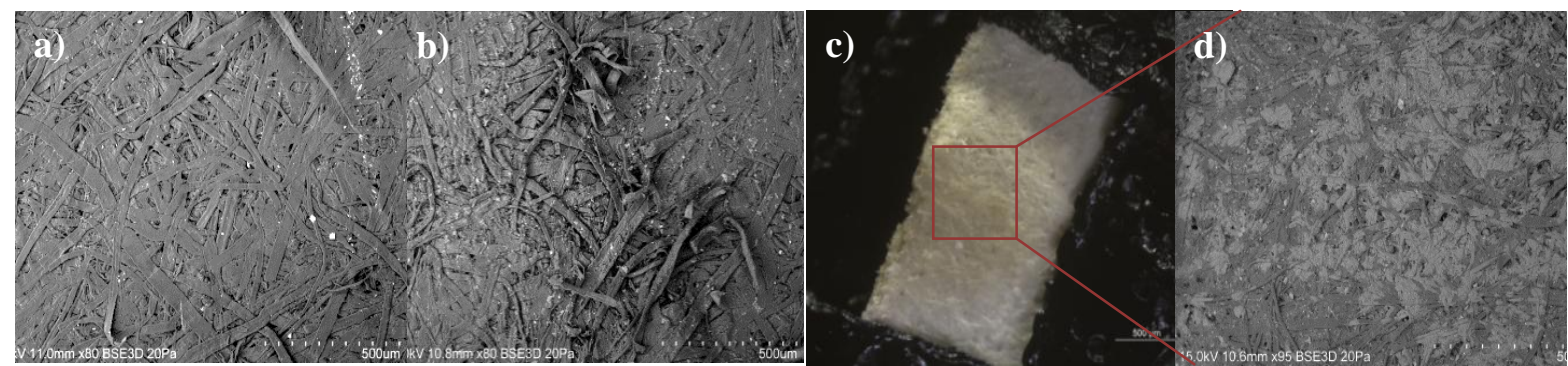

Figure 1. SEM micrographs of sample a) P3, undamaged area; b) P3, foxed area; c) P7, optical microscopy image; d) P7, foxed area.

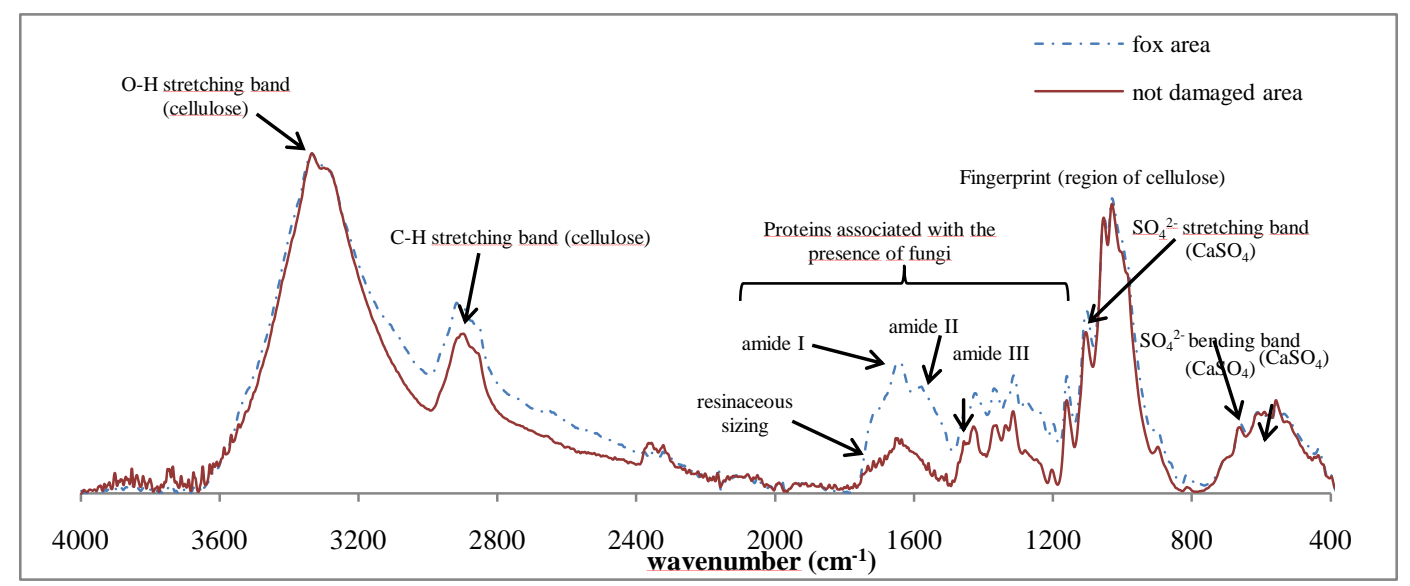

Figure 2. ATR-FT-IR spectra of P3 sample. 